\title{
Segregação ocupacional por sexo no mercado de trabalho brasileiro: uma análise de decomposição para o período 2004-2015
}

\author{
Diego Camargo Botassio* \\ Daniela Verzola Vaz ${ }^{\star \star}$
}

\begin{abstract}
Este artigo analisa a evolução da segregação ocupacional por sexo no mercado de trabalho brasileiro de 2004 a 2015. Além da mensuração da segregação por meio de indicadores tradicionais, como o índice de dissimilaridade e o de Gini, utiliza-se a classe de medidas aditivamente decomponíveis proposta por Hutchens (2004), que permite decompor a segregação em duas parcelas: uma relacionada à segregação entre grandes grupos ocupacionais; e outra que corresponde a uma soma ponderada dos níveis de segregação dentro desses grupamentos. Os resultados mostram que a segregação aumentou entre 2004 e 2015, revertendo a tendência de queda que vinha sendo relatada na literatura referente a anos anteriores a esse período. A análise de decomposição indica que tal crescimento foi impulsionado pela segregação entre os grandes grupos ocupacionais, portanto, entre grupos com ocupações mais heterogêneas entre si. Conclui-se que, à medida que o nível da participação feminina no mercado de trabalho se estabiliza, o processo de integração das ocupações segundo o sexo também apresenta seus primeiros sinais de esgotamento.
\end{abstract}

Palavras-chave: Mercado de trabalho. Segregação ocupacional por sexo. Brasil.

\footnotetext{
*Universidade Estadual de Maringá (UEM), Maringá-PR, Brasil (diegocbotassio@gmail.com; https://orcid.org/0000-00018932-122X).

** Universidade Federal de São Paulo (Unifesp), São Paulo-SP, Brasil (daniela.vaz@unifesp.br; https://orcid.org/00000003-4505-6318).
} 


\section{Introdução}

De acordo com a Pesquisa Nacional por Amostra de Domicílios Contínua (PNADC/IBGE) do $2^{\circ}$ trimestre de 2019, 93,6\% dos trabalhadores domésticos no Brasil são mulheres. Entre as babás, esse percentual é ainda maior ( $96,1 \%)$. Em contraste, as engenheiras civis correspondem a menos de $20 \%$ dos profissionais da categoria. Esses valores ilustram a segregação ocupacional por sexo no mercado de trabalho, tendo em vista que se distanciam muito dos percentuais de mulheres observados na força de trabalho $(45,1 \%)$ e na população ocupada $(44,1 \%)$.

A distribuição desigual de homens e mulheres nas diferentes ocupações seria uma característica fortuita do mercado de trabalho, caso as mulheres não estivessem concentradas nos setores e ocupações que pagam menos e apresentam menor status social - apesar de serem, em média, mais escolarizadas do que os homens. ${ }^{1}$ Vários estudos empíricos confirmam a importância da segregação ocupacional como um dos principais determinantes do diferencial salarial por sexo no Brasil (BARROS; MACHADO; MENDONÇA, 1997; KASSOUF, 1998; OMETTO et al., 1999; OLIVEIRA, 2003; MADALOZZO, 2010), o que contribui para a perpetuação das desigualdades sociais entre os gêneros e dos maiores níveis de pobreza feminina.

Em vista de sua relevância, a análise da segregação ocupacional tem sido objeto de estudo na literatura internacional desde o final da década de 1960 (GROSS, 1968; OPPENHEIMER, 1970). Em nível nacional, os primeiros trabalhos sobre o tema remontam aos anos 1990, quando foram analisados dados da década de 1980 (ver OMETTO; HOFFMANN; ALVES, 1997; OLIVEIRA, 2001). A revisão da literatura nacional permite constatar que, embora tenha diminuído, a segregação no Brasil ainda está longe de ser eliminada (KING, 2009; SALARDI, 2016), o que explica a permanência do tema na agenda de pesquisa sobre mercado de trabalho e gênero no país. A maioria dos trabalhos, entretanto, analisa a segregação de um ponto de vista estático, isto é, em um ano específico, visando, em última instância, verificar como esse fenômeno contribui para o hiato salarial entre homens e mulheres. Não há, na literatura recente, estudos que tenham realizado uma análise intertemporal da segregação para o Brasil, a fim de identificar tendências ao longo do tempo no processo de integração das ocupações segundo o sexo. ${ }^{2} 0$ presente artigo visa preencher essa lacuna, a partir da análise dos dados da Pesquisa Nacional por Amostra de Domicílios (PNAD/IBGE) de 2004 a 2015. Além da mensuração da segregação por meio de indicadores tradicionais, como o índice de dissimilaridade e o índice de Gini para segregação, utiliza-se a classe de medidas aditivamente decomponíveis proposta por Hutchens (2004), que permite decompor a segregação (total) em duas parcelas: uma referente à segregação entre grandes grupos ocupacionais; e outra que corresponde a uma soma ponderada dos níveis de segregação dentro desses grupamentos. Essa abordagem

\footnotetext{
$\overline{1}$ Beltrão e Alves (2009) mostram que entre os Censos Demográficos de 1980 e 1991 as mulheres conseguiram reverter o hiato na educação historicamente favorável aos homens, passando a acumular maior número médio de anos de estudo do que eles.

${ }^{2}$ A exceção fica por conta de Salardi (2016). Essa autora, contudo, analisou o período 1995-2006.
} 
ainda é pouco adotada na literatura (MORA; RUIZ-CASTILLO, 2003; HUTCHENS, 2004), mas possibilita concluir se a tendência na segregação (queda ou aumento) pode ser atribuída em maior parte à segregação entre ocupações mais homogêneas ou mais heterogêneas.

Este trabalho está dividido em quatro seções, além desta introdução. A seção a seguir mostra que, apesar do processo de diversificação das atividades desempenhadas pelas mulheres no mercado de trabalho brasileiro a partir da década de 1970, a segregação ocupacional por sexo se mantém. As razões para sua existência e persistência são brevemente discutidas. Posteriormente apresentam-se a base de dados e as medidas de segregação utilizadas. Também é realizada uma análise descritiva da distribuição de homens e mulheres em grupamentos ocupacionais, comparando os anos de 2004 e 2015 . Na sequência, analisam-se as tendências de longo prazo na evolução da segregação por sexo no período 2004-2015, quando as ocupações são agregadas em grandes grupos ocupacionais e em subgrupos ocupacionais principais. Por fim, é feita a decomposição da segregação total nos componentes entre e intragrupos. A última seção apresenta as conclusões do estudo.

\section{Antecedentes}

0 ingresso das mulheres no mercado de trabalho brasileiro ganhou intensidade a partir de meados dos anos 1970. De acordo com os dados dos Censos Demográficos (IBGE), entre 1970 e 1991 a taxa de participação feminina ${ }^{3}$ passou de $18,5 \%$ para 32,9\%. Entre os fatores que impulsionaram o fenômeno - já amplamente discutido na literatura - podem ser citados o aumento da escolaridade feminina, a queda das taxas de fecundidade e os processos de industrialização e urbanização, que disseminaram novos costumes e hábitos de consumo (COSTA, 1990; BRUSCHINI; LOMBARDI, 1996; SCORZAFAVE; MENEZES-FILHO, 2001; SOARES; IZAKI, 2002; BRUSCHINI; LOMBARDI, 2003).

Até os anos 1970, as mulheres tinham maior presença no trabalho doméstico não remunerado, invisível aos olhos do mercado. Mesmo no setor agrícola, em que a mulher contribuía para a agricultura familiar, sua atividade preponderante era considerada a de dona de casa, razão pela qual, via de regra, ela era classificada como economicamente inativa (BRUSCHINI, 1994, p. 179).

A partir de 1970, as mulheres passaram a desempenhar crescentemente ocupações no setor terciário, particularmente na prestação de serviços. Em 1981, os setores de atividade econômica que mais absorviam as trabalhadoras eram prestação de serviços (com 31,8\% delas), atividade agrícola (19,8\%) e social (16,6\%), segundo dados da PNAD tabulados por Bruschini (1994).

Ao longo dos anos 1980, as mulheres avançaram nos setores de comércio, atividades sociais e administração. Esse processo foi mais marcante no Nordeste, região que também

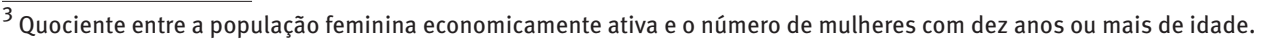


era caracterizada por um maior peso relativo da administração pública, sobretudo entre as mulheres (BRUSCHINI, 1994).

A tendência de inserção das brasileiras nesses setores teve continuidade nos anos 1990. Segundo Wajnman, Queiroz e Liberato (1998), as ocupações que mais absorveram a mão de obra feminina nessa década foram a de conta própria no comércio de mercadorias (por exemplo, no comércio ambulante de cosméticos), a de empregadas domésticas com e sem carteira de trabalho assinada, a de funcionárias públicas nas atividades sociais (enfermeiras, professoras, serventes e cozinheiras) e a de funcionárias da administração pública (como auxiliares administrativas e de escritório, serventes e faxineiras). As tabulações de Araújo e Ribeiro (2001) com base nos dados da PNAD de $1995^{4}$ mostram que, nessa época, os grupos de ocupações administrativas e ligadas ao comércio e atividades auxiliares já haviam se tornado integrados, isto é, absorviam percentuais de homens e de mulheres similares às suas participações na força de trabalho. Contudo, a prestação de serviços (categoria que inclui os empregados domésticos) e as ocupações técnico-científicas permaneciam predominantemente femininas, ao passo que os grupos ocupacionais indústria, transporte e comunicações, masculinos. 0 nível geral de segregação permanecia elevado: 0 índice de dissimilaridade, calculado com base na agregação das ocupações a um dígito, ${ }^{5}$ mostrava que entre $34 \%$ (nas regiões Norte e Sul) e $40 \%$ (no Nordeste) da força de trabalho feminina deveria ser realocada para eliminar sua sobre (ou sub) representação em determinados grupos ocupacionais.

Os anos 2000 caracterizaram-se pela redução da velocidade de entrada da mulher no mercado de trabalho. Ao longo dessa década, a taxa de participação feminina passou de 44,1\% para $48,9 \%$, de acordo com os dados dos Censos Demográficos. 0 processo de diversificação da atividade feminina, porém, teve continuidade. Segundo Salas e Leite (2007), o grau de segregação setorial por sexo entre 1995 e 2004 - aferido por meio do índice de Karmel-MacLachlan, ${ }^{6}$ com base nos microdados da PNAD - reduziu-se em 4,8\%. 0 setor que mais contribuiu para essa queda foi a indústria de transformação, em que a participação feminina passou de $27,3 \%$ em 1995 para 37,1\% em 2004, alterando a estrutura por sexo dessa atividade. A presença feminina no setor terciário, por seu turno, conservou-se significativa.

Apesar do aumento da participação feminina e da diversificação das atividades desempenhas pelas mulheres no mercado de trabalho brasileiro a partir da década de 1970, a segregação ocupacional por sexo não foi eliminada. Em uma das poucas análises intertemporais sobre o fenômeno, Oliveira (2003) constata, com base no cálculo de índices sumários, que a segregação no Brasil não declinou entre 1981 e 1999 e a distribuição de homens e mulheres em ocupações predominantemente femininas, masculinas ou integradas pouco

\footnotetext{
${ }_{4}^{4}$ A análise é restrita a moradores de regiões urbanas, com idade entre 25 e 50 anos, que trabalhavam mais de 20 horas por semana em ocupações não agrícolas, não frequentavam escola e tinham renda mensal do trabalho positiva.

${ }^{5}$ Os grupos ocupacionais considerados pelos autores foram: indústria; técnico, científico, artístico; administrativo; comércio e atividades auxiliares; transporte e comunicação; prestação de serviços; e outra ocupação.

${ }^{6} \mathrm{O}$ índice de Karmel-MacLachlan é definido como duas vezes o produto entre a participação de homens e mulheres no mercado de trabalho e o valor do índice de dissimilaridade (BOTASSIO, 2017). Ver a seção Medidas de segregação, para detalhes sobre o índice de dissimilaridade.
} 
se alterou nesse período. Em contraste, Salardi (2016) conclui que a segregação aumentou sutilmente no início dos anos 1990, mas decresceu substancialmente de 1995 a 2006. Essa aparente contradição nos resultados é explicada pelo fato de as medidas de segregação serem sensíveis ao nível de agregação das ocupações em categorias. Quanto mais desagregados forem os grupos ocupacionais, maior é o nível de segregação aferido (DEGRAFF; ANKER, 2004). Além disso, conforme será discutido na próxima seção, diferentes medidas captam distintos aspectos da segregação. Essas diferenças inviabilizam a comparação de resultados de trabalhos com metodologias diferentes.

Entre os fatores que explicam a persistência da segregação ocupacional por sexo no mercado de trabalho, encontram-se, de um lado, a discriminação de emprego - que resulta na menor contratação de mulheres para o exercício de ocupações tidas como "masculinas" - e, de outro, a preferência feminina por atividades e carreiras identificadas com o papel social atribuído à mulher (SALAS; LEITE, 2007). É complexo precisar o quanto do atual grau de segregação ocupacional decorre do tratamento desigual por parte dos empregadores e o quanto é fruto da internalização de estereótipos culturais por parte das próprias mulheres (ARAÚJO; RIBEIRO, 2001), porém, é possível afirmar que ambas as explicações estão sustentadas, em última instância, nas relações de gênero construídas socialmente.

As relações sociais de gênero se expressam por meio da chamada divisão sexual do trabalho. Esse conceito da sociologia se assenta na premissa de que há uma separação e uma hierarquização do trabalho desempenhado por homens e mulheres: aos primeiros é designado o trabalho produtivo e com maior valor social, ao passo que às mulheres cabem prioritariamente as funções na esfera reprodutiva, que são realizadas gratuitamente e permanecem invisíveis aos olhos do mercado (HIRATA; KERGOAT, 2007; KERGOAT, 2009). A incorporação das mulheres ao mercado do trabalho deu-se de acordo com os princípios dessa divisão. Por esse motivo, elas se encontram concentradas em profissões que representam as formas socializadas de funções que lhes são tradicionalmente atribuídas dentro da família, como as que envolvem cuidados (por exemplo, enfermeiras, assistentes sociais, professoras), ou as que requerem habilidades relacionadas às tarefas domésticas (trabalhadoras domésticas, cozinheiras, costureiras, etc.).

As modalidades da divisão sexual do trabalho mudam ao longo do tempo (HIRATA; KERGOAT, 2007). Até os anos 1970 prevalecia o modelo tradicional, que atribui o cuidado dos filhos e da casa inteiramente às mulheres e o papel de provedor exclusivamente aos homens. Com a crescente participação feminina no mercado de trabalho, emergiu o modelo de conciliação, caracterizado pelo desempenho feminino tanto de atividades profissionais como da maior parte dos encargos familiares. Coexiste, ainda, o modelo da delegação, pautado na transferência das tarefas domésticas e de cuidado dos filhos a outras mulheres. Apesar de suas diferenças, esses três modelos partilham o princípio comum de que as responsabilidades domésticas e familiares são de competência das mulheres, sendo que a articulação entre as esferas produtiva e reprodutiva é um problema a ser resolvido por elas (HIRATA; KERGOAT, 2007, 2008). 
Os modelos de conciliação e delegação tornaram-se possíveis graças ao aumento acelerado dos empregos em serviços, em ocupações como faxineiras, empregadas domésticas, babás e cuidadoras - desempenhadas quase exclusivamente por mulheres. Esse processo resultou na polarização (HAKIM, 1996) ou dualização (KERGOAT, 2009) do emprego feminino, com a coexistência, de um lado, de mulheres escolarizadas em profissões de prestígio e cargos de destaque no mercado de trabalho e, de outro, de mulheres em ocupações mal remuneradas e com baixo grau de proteção social. ${ }^{7}$

A próxima seção descreve a base de dados e as medidas de segregação utilizadas neste trabalho.

\section{Base de dados e metodologia}

Base de dados

Para a realização deste trabalho foram utilizados os microdados da Pesquisa Nacional por Amostra de Domicílios (PNAD), realizada pelo Instituto Brasileiro de Geografia e Estatística (IBGE) até 2015 e descontinuada após esse ano, tendo sido substituída pela PNAD Contínua, que adota metodologia diferente para a coleta de dados. A PNAD investigava, com periodicidade anual, características gerais da população e informações relativas a migração, educação, trabalho, rendimento, fecundidade e habitação. Sua cobertura geográfica tornou-se nacional a partir de 2004, pois até então não eram coletadas informações das áreas rurais de Rondônia, Acre, Amazonas, Roraima, Pará e Amapá.

A partir de 2002 a PNAD passou a adotar a Classificação Brasileira de OcupaçõesDomiciliar (CBO-Domiciliar), que é uma adaptação da Classificação Brasileira de Ocupações (CBO) para pesquisas domiciliares. Cumpre destacar que a natureza das diferenças entre a CBO-Domiciliar e a classificação de ocupações utilizada até 2001 impossibilita recompor, sequer ao nível mais agregado, os grupamentos de ocupações construídos para a divulgação da PNAD a partir de 2002. Por esse motivo, a comparação dos níveis de segregação ocupacional antes e após 2002 não é possível. Considerando-se, ainda, que a pesquisa adquiriu abrangência nacional apenas a partir de 2004, optou-se por adotar como horizonte de análise neste trabalho o período 2004-2015. Em 2010, entretanto, a PNAD não foi a campo, em razão da realização do Censo Demográfico; por isso, as estimativas referentes a esse ano foram obtidas pela interpolação linear dos valores obtidos em 2009 e 2011.

A CBO-Domiciliar, adotada a partir de 2002, é uma classificação a cinco dígitos que distribui as ocupações em grandes grupos ocupacionais (identificados pelo primeiro dígito), subgrupos principais (identificados pelos dois primeiros dígitos), subgrupos (três primeiros dígitos) e grupos de base ou famílias ocupacionais (quatro primeiros dígitos). Para fins deste trabalho, foram considerados os dados ocupacionais de dois dígitos, que

\footnotetext{
${ }^{7}$ A polarização do mercado de trabalho feminino apresenta uma inter-relação com as desigualdades de raça, tendo em vista que as mulheres em posição de destaque no mercado de trabalho são predominantemente brancas, ao passo que aquelas que desempenham funções precárias, com baixos níveis salariais e de proteção social, são, em sua maioria, negras.
} 
organizam as ocupações em 48 subgrupos ocupacionais principais. Segundo DeGraff e Anker (2004), dados ocupacionais de dois dígitos têm um detalhamento aceitável para análises baseadas em índices de segregação como o de dissimilaridade.

Para a realização da decomposição da segregação total - medida a dois dígitos - na parcela intra e entre grupos, foram considerados os oito grandes grupos ocupacionais a um dígito, a saber: dirigentes em geral; profissionais das ciências e das artes; técnicos de nível médio; trabalhadores de serviços administrativos; trabalhadores dos serviços, vendedores e prestadores de serviços do comércio; ${ }^{8}$ trabalhadores agrícolas; trabalhadores da produção de bens e serviços industriais e de reparação e manutenção; e membros das Forças Armadas e auxiliares.

Cabe notar que foram eliminados da amostra os indivíduos com ocupações mal definidas, bem como aqueles para os quais a ocupação não foi captada, por serem economicamente inativos ou encontrarem-se desocupados na semana de referência da pesquisa. Isso implica que a análise foi circunscrita aos indivíduos com dez anos ou mais idade, tendo em vista que as características de trabalho e rendimento somente eram captadas de forma permanente na PNAD para os moradores a partir dessa idade.

A Tabela 1 apresenta a amostral final, após os mencionados recortes, para todos os anos da PNAD que foram contemplados na análise. Em 2004 havia 183.705 observações e, em $2015,165.168$, as quais, expandidas segundo os pesos fornecidos pela pesquisa, correspondiam a, respectivamente, 85.190 .616 e 95.361 .307 pessoas ocupadas no mercado de trabalho. Todas as análises e estimações ao longo do trabalho levaram em conta o peso amostral associado a cada indivíduo na amostra.

TABELA 1

Tamanho da amostra e da amostra expandida de indivíduos com dez anos ou mais de idade ocupados no mercado de trabalho na semana de referência da PNAD (1)

Brasil - 2004-2015

\begin{tabular}{ccc}
\hline Anos & Amostra & Amostra expandida \\
\hline 2004 & 183.705 & 85.190 .616 \\
2005 & 190.493 & 87.670 .074 \\
2006 & 193.276 & 89.631 .186 \\
2007 & 188.969 & 90.819 .311 \\
2009 & 189.034 & 93.401 .904 \\
2011 & 191.810 & 92.686 .490 \\
2012 & 170.451 & 94.704 .877 \\
2013 & 173.470 & 96.053 .496 \\
2014 & 172.284 & 96.626 .292 \\
2015 & 176.547 & 99.409 .069 \\
\hline
\end{tabular}

Fonte: PNAD/IBGE 2004-2015. Elaboração dos autores.

(1) Exclusive trabalhadores com ocupações mal definidas.

\footnotetext{
${ }^{8}$ Após a delimitação da amostra em ocupações de dois dígitos, os grupamentos "trabalhadores dos serviços" e "vendedores e prestadores de serviços do comércio" ficaram classificados com uma ocupação de dois dígitos cada um. Assim, foi necessário agrupá-los para ser possível a análise da decomposição.
} 


\section{Medidas de segregação}

Diferentes medidas captam distintos aspectos da segregação. Por exemplo, uma medida pode ser muito sensível a mudanças na composição por sexo de ocupações com escassez de mulheres, ao passo que outra pode ser pouco sensível ao que ocorre nessas mesmas ocupações. Por esse motivo, é usual adotarem-se diversos indicadores de segregação na análise desse fenômeno. Neste artigo foram empregados o índice de dissimilaridade e o índice de Gini para segregação - os mais utilizados em trabalhos empíricos na literatura -, bem como a classe de medidas de segregação aditivamente decomponíveis proposta por Hutchens (2004). Para apresentá-los, preliminarmente é necessário formalizar a notação utilizada.

Considere que mulheres (representadas por $M$ ) e homens (indicados por $H$ ) encontram-se distribuídos em $J$ categorias ocupacionais (ou, simplesmente, ocupações). Assim, $M_{j}$ e $H_{j}$ indicam, respectivamente, o número de mulheres e de homens alocados na $j$-ésima ocupação, com $j=1, \ldots, J$. 0 número total de mulheres ocupadas é dado por $M=\sum_{j=1}^{J} M_{j}$, enquanto a participação da $j$-ésima ocupação no total de mulheres é $m_{j}=M_{j} / M$. De modo análogo, definem-se as quantidades $H=\sum_{j=1}^{J} H_{j}$ e $h_{j}=H_{j} / H$ em referência aos homens.

Considere a matriz $\mathrm{X}$, de ordem $2 \times \mathrm{J}$, cujos elementos são os totais de homens e mulheres nas $J$ ocupações da economia. Por definição, uma medida de segregação é uma função que atribui à matriz $\mathrm{X}$ um número real não negativo. Uma medida de segregação $\Omega=\Omega(\mathrm{X})$ tem como argumento a matriz X (elemento de seu domínio). Diz-se que não há segregação quando a proporção de mulheres no número de pessoas ocupadas for a mesma em todas as ocupações. Em geral, nessa situação uma medida de segregação assume seu menor valor (zero). No extremo oposto, a segregação é máxima quando cada ocupação é desempenhada exclusivamente por homens ou por mulheres.

A medida de segregação mais utilizada na literatura é o índice de dissimilaridade (D), proposto por Jahn, Schmid e Schrag (1947). Segundo os autores, esse índice corresponde à metade da soma dos desvios entre as participações de cada ocupação no total de mulheres e de homens, conforme a expressão:

$D=\frac{1}{2} \sum_{j=1}^{J}\left|m_{j}-h_{j}\right|$

Nota-se que o índice de dissimilaridade está limitado entre zero e 1, em que zero indica o caso extremo de total integração, e 1 o caso de segregação máxima.

Outra medida muito comum é o índice de Gini para segregação $(G)$, cujo uso se disseminou após o trabalho de Duncan e Duncan (1955). É impressionante a diversidade de expressões para o índice de Gini descritas na literatura. ${ }^{9}$ Dentre elas, segundo Hoffmann, Botassio e Jesus (2019), tem-se:

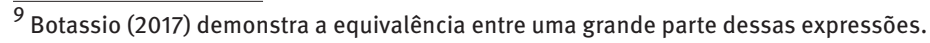


$G=\frac{1}{2 M H} \sum_{i=1}^{J} \sum_{j=1}^{J}\left|\frac{M_{i}}{H_{i}}-\frac{M_{j}}{H_{j}}\right| H_{i} H_{j}$

para todo $i$ e $j$.

Outra maneira de calcular o índice de Gini para segregação é por meio da curva de segregação. Para construí-la deve-se, primeiramente, ordenar as ocupações segundo valores não decrescentes da razão $M_{j} / H_{j}$. Em seguida, calculam-se os somatórios $\Psi_{j}=\sum_{i=1}^{j} h_{i}$ e $\rho_{j}=\sum_{i=1}^{j} m_{i}$, que correspondem, respectivamente, à proporção acumulada de homens e de mulheres até a j-ésima ocupação. A curva de segregação é obtida ao se unir, no plano cartesiano, a origem $(0,0)$ aos pontos $\left(\rho_{j}, \Psi_{j}\right)$ com $j=1, \ldots, J$. Seja $\beta$ a área compreendida entre essa curva e o eixo das abscissas. Então, o índice de Gini para segregação é dado por $G=1-2 \beta$. Dado que $0 \leq \beta \leq 0,5$, verifica-se que $0 \leq G \leq 1$, que são os mesmos limites de variação do índice de dissimilaridade. Cumpre notar que a curva de segregação também pode ser utilizada em análises empíricas, conforme será feito mais adiante.

Uma medida apropriada para captar diferentes aspectos da segregação é a classe de medidas aditivamente decomponíveis proposta por Hutchens (2004), doravante medida geral de segregação $\left(I_{\varepsilon}\right)$ :

$I_{\varepsilon}=\frac{1}{\varepsilon(1-\varepsilon)}\left(1-\sum_{j=1}^{J} h_{j}^{\varepsilon} m_{j}^{1-\varepsilon}\right)$

Seu limite inferior é zero - caso extremo de ausência de segregação - e seu valor máximo, para o caso em que $0<\varepsilon<1$, é $1 /[\varepsilon(1-\varepsilon)]$ - situação de extrema segregação. Note que a medida geral de segregação é função do parâmetro $(\varepsilon),{ }^{10}$ que, em princípio, pode assumir qualquer valor real. ${ }^{11}$ Índices com diferentes valores do parâmetro mensuram diferentes aspectos da segregação. Por exemplo, caso $\varepsilon \rightarrow 0$, obtém-se o índice $T$ de Theil para segregação, que é uma medida mais sensivel a mudanças em ocupações com poucos homens. Sua expressão é dada por $T=\sum_{j=1}^{J} m_{j} \ln \left(m_{j} / h_{j}\right)$. Conforme se vê, essa medida não é definida quando existe pelo menos uma ocupação sem homens. Por outro lado, quando $\varepsilon \rightarrow 1$, tem-se o $L$ de Theil $\left[L=\sum_{j=1}^{J} h_{j} \ln \left(h_{j} / m_{j}\right)\right]$, que é mais sensível a mudanças em ocupações com poucas mulheres, mas não é definido quando há ao menos uma ocupação sem mulheres. Neste trabalho será utilizada a medida geral para os casos em que $\varepsilon \rightarrow 0$, $\varepsilon \rightarrow 1, \varepsilon=0,1, \varepsilon=0,5^{12}$ e $\varepsilon=0,9$.

Uma propriedade interessante da medida geral de segregação é que ela é aditivamente decomponível, isto é, a segregação (total) pode ser decomposta em duas parcelas: uma referente à segregação entre grupamentos de ocupações e outra que corresponde a uma soma ponderada das medidas de segregação dentro desses grupamentos. Considere que as $J$ ocupações - geralmente consideradas sob um sistema de classificação de dois

\footnotetext{
10 Segundo Botassio e Hoffmann (2020), esse parâmetro é uma medida de "aversão à segregação".

${ }^{11}$ Para $\varepsilon=0$ e $\varepsilon=1$, a medida geral de segregação $\left(I_{\varepsilon}\right)$ não é definida, sendo necessário defini-la utilizando a regra de l'Hôpital e o limite quando $\varepsilon$ tende a zero ou 1. Para mais detalhes, ver Botassio (2017).

12 Quando $\varepsilon=0,5$, a medida geral de segregação é igual a quatro vezes o índice raiz quadrada de Hutchens (2001).
} 
dígitos, portanto, mais desagregado - possam ser agrupadas em $n_{g}$ grupos - de acordo com a classificação a um dígito, por exemplo. Essa classificação de ocupações em grupos deve obedecer a algum critério de similaridade preestabelecido, de modo que todas as ocupações sejam classificadas em apenas um grupo. Se $I_{\varepsilon g}$ indica a segregação dentro do g-ésimo grupo $\left(g=1, \ldots, n_{g}\right)$ e $m_{g}$ e $h_{g}$ são as participações de mulheres e homens do g-ésimo grupo no total de mulheres e homens, respectivamente, a decomposição aditiva da medida geral é: ${ }^{13}$

$I_{\varepsilon}=\sum_{g=1}^{n_{g}} h_{g}^{\varepsilon} m_{g}^{1-\varepsilon} I_{\varepsilon g}+\frac{1}{\varepsilon(1-\varepsilon)}\left(1-\sum_{g=1}^{n_{g}} h_{g}^{\varepsilon} m_{g}^{1-\varepsilon}\right)$

O termo do lado esquerdo da equação (4) é a segregação total (considerando ocupações de dois dígitos). 0 primeiro termo do lado direito da expressão é a segregação dentro dos grupos. Essa parcela é constituída pela soma das medidas de segregação dentro dos grupos $\left(I_{\varepsilon g}\right)$, ponderadas pelos fatores $h_{g}^{\varepsilon} m_{g}^{1-\varepsilon}$. O segundo termo do lado direito da equação é a segregação entre os grupos. Note que a decomposição (4) somente é válida quando são consideradas unicamente as ocupações pertencentes ao grupo $g$ para o cálculo da medida $I_{\varepsilon g}$.

Cumpre notar que o índice de dissimilaridade não atende à propriedade de adição decomponível, ao passo que o índice de Gini somente a satisfaz quando os grupos de ocupações são criados a partir da ordenação das ocupações segundo as razões $M_{j} / H_{j}$.

\section{Resultados}

Entre 2004 e 2015, a proporção de mulheres entre os indivíduos ocupados no mercado de trabalho brasileiro aumentou ligeiramente, passando de $41,8 \%$ para $42,6 \%$, com um pico em 2014 (43,1\%). Essa evolução é apresentada no Gráfico 1.

Apesar da leve tendência de aumento na proporção de mulheres no longo prazo, verifica-se queda desse percentual entre 2014 e 2015 (-1\%), que está relacionada com a crise econômica registrada no país a partir de meados de 2014. De modo semelhante, entre 2009 e 2011, a crise do subprime teve seus desdobramentos sobre a economia brasileira, resultando em diminuição da participação feminina entre os ocupados. Em períodos de oscilações, crises econômicas e inseguranças institucionais, as mulheres estão mais suscetíveis a perderem o emprego do que os homens. Além disso, uma vez desempregadas, elas apresentam menor probabilidade de obtenção de emprego e maior chance de transição para a inatividade econômica do que eles (REIS; AGUAS, 2014; REIS, 2015).

\footnotetext{
${ }^{13}$ Para derivar a expressão (4) a partir da (3), deve-se seguir dois procedimentos. Primeiro, o somatório na expressão (3) deve ser substituído por dois somatórios: o primeiro $\operatorname{com} g=1$ a $n_{g}$ (representando os grupos); e o outro com o somatório de todas as ocupações do $g$-ésimo grupo, com as devidas adaptações para os subíndices. Depois, adicionando e subtraindo a expressão $I_{\varepsilon g}$ dentro dos parênteses da expressão, com alguma álgebra, encontra-se a equação (4). Para mais detalhes, ver Botassio (2017, p. 37-39) e Hoffmann, Botassio e Jesus (2019, p. 312-314).
} 
GRÁFICO 1

Proporção de mulheres entre os indivíduos ocupados no mercado de trabalho Brasil - 2004-2015

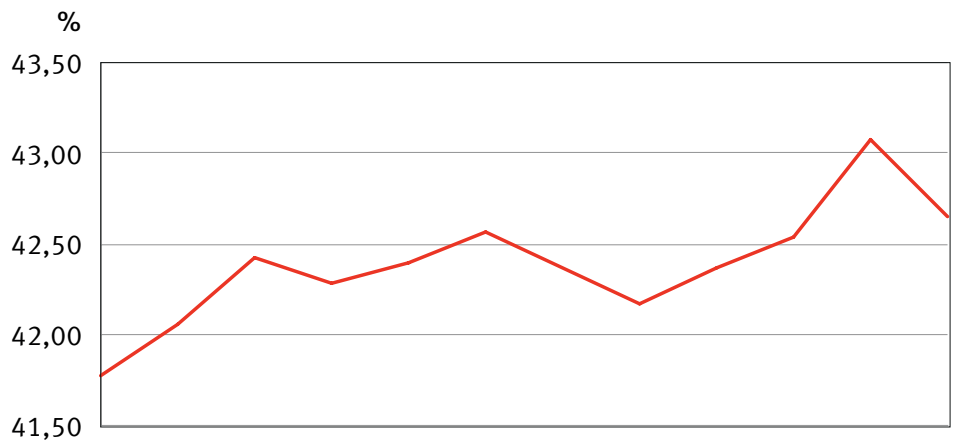

200420052006200720082009201020112012201320142015

Fonte: PNAD/IBGE 2004-2015. Elaboração dos autores.

Nota: 0 valor referente a 2010 resulta de interpolação linear.

A Tabela 2 apresenta a proporção feminina $\left(P_{j}\right)^{14}$ e a razão entre o número de mulheres e o de homens $\left(M_{j} / H_{j}\right)$ nos grandes grupos ocupacionais da CBO-Domiciliar, em 2004 e 2015.

TABELA 2

Proporção de mulheres $\left(P_{j}\right.$ em \%) e razão mulheres/homens $\left(M_{j} / H_{j}\right)$, segundo grandes grupos ocupacionais

Brasil - 2004-2015

\begin{tabular}{lrrrrr}
\hline \multicolumn{1}{c}{ Grandes grupos ocupacionais } & \multicolumn{2}{c}{$\mathbf{2 0 0 4}$} & & \multicolumn{2}{c}{$\mathbf{2 0 1 5}$} \\
\cline { 2 - 3 } \cline { 5 - 6 } & $P_{j}$ & $M_{j} / H_{j}$ & & $P_{j}$ & $M_{j} / H_{j}$ \\
\hline Dirigentes em geral & 33,92 & 0,51 & & 37,10 & 0,59 \\
Profissionais das ciências e das artes & 59,33 & 1,46 & & 61,75 & 1,61 \\
Técnicos de nível médio & 46,38 & 0,87 & & 43,92 & 0,78 \\
Trabalhadores de serviços administrativos & 58,71 & 1,42 & 63,43 & 1,73 \\
Trab. dos serviços, vendedores e prestadores de serviços do comércio & 60,71 & 1,55 & 61,13 & 1,57 \\
Trabalhadores agrícolas & 32,08 & 0,47 & 29,35 & 0,42 \\
Trab. da produção de bens e serviços industriais, reparação e & 16,87 & 0,20 & & 13,07 & 0,15 \\
manutenção & & & & \\
Membros das Forças Armadas e auxiliares & $\mathbf{4 , 9 4}$ & $\mathbf{0 , 0 5}$ & & $\mathbf{8 , 9 8}$ & 0,10 \\
Total & $\mathbf{4 1 , 7 7}$ & $\mathbf{0 , 7 2}$ & $\mathbf{4 2 , 6 5}$ & $\mathbf{0 , 7 4}$ \\
\hline
\end{tabular}

Fonte: PNAD/IBGE 2004-2015. Elaboração dos autores.

Os grupamentos ocupacionais com maioria feminina são: profissionais das ciências e das artes; trabalhadores de serviços administrativos; e trabalhadores dos serviços, vendedores e prestadores de serviços do comércio. Esses grupos viram a participação das mulheres elevar-se ainda mais de 2004 a 2015. Entre os profissionais das ciências e das artes, por exemplo, elas passaram de $59,3 \%$ para $61,7 \%$, o que representa um aumento de 2,4 pontos percentuais ou $4,1 \%$. Cumpre notar que os grandes grupos ocupacionais da CBO são definidos não apenas de acordo com a similaridade nas atividades executadas,

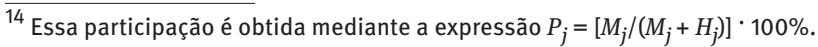


mas também segundo o nível de competência requerido. Os profissionais das ciências e das artes, em particular, reúnem ocupações de maior complexidade, para as quais é necessário deter o nível superior de ensino. Dessa maneira, o avanço das mulheres nesse grupamento reflete o aumento de sua escolaridade e, em particular, de sua presença no ensino superior no Brasil.

Em contrapartida, nos grupos ocupados majoritariamente por homens, o percentual de mulheres declinou, com redução de 5,3\% entre os técnicos de nível médio, 8,5\% entre os trabalhadores agrícolas e $22,5 \%$ no grupo de trabalhadores da produção de bens e serviços industriais e de reparação e manutenção. Entre as exceções estão os dirigentes em geral, grupamento predominantemente masculino no qual o percentual de mulheres aumentou, passando de 33,9\% em 2004 para 37,1\% em 2015.

0 aumento da presença feminina entre os dirigentes em geral e profissionais das ciências e das artes espelha a polarização do emprego feminino. De um lado, há um conjunto de mulheres em profissões intelectuais superiores, que desfrutam de bons salários e ocupações de prestígio social, como médicas, advogadas, juízas, arquitetas, jornalistas, professoras universitárias, pesquisadoras, assalariadas do ramo da publicidade e da arte, etc. De outro, há um contingente feminino expressivo que se mantém em ocupações frequentemente mal remuneradas, pouco valorizadas e sem reconhecimento social. Estes são empregos muitas vezes informais ou de caráter temporário - como nos serviços domésticos e no comércio -, quase sempre sem perspectiva de carreira (HIRATA, 2009).

Também é digno de nota o caso dos membros das Forças Armadas e auxiliares. Embora apresente a menor proporção de mão de obra feminina, esse grupamento teve o maior aumento relativo na proporção de mulheres ( $81,8 \%$ ), que passaram de quase $5 \%$ para $9 \%$ dos ocupados entre 2004 e 2015 . Em valores absolutos, elas saltaram de 32.422 para 75.737 militares nesse período. Esse fato deveu-se à recente admissão delas nessa ocupação, no Brasil. No Exército, a instituição do Serviço Militar Feminino Voluntário para médicas, farmacêuticas, dentistas, veterinárias e enfermeiras, a partir de 1996, ampliou o espaço de atuação feminina. Em 2012, a Lei n. 12.705 passou a permitir a atuação das mulheres também como combatentes. A Aeronáutica, por sua vez, foi a primeira das três Forças a admitir mulheres não apenas nas atividades de apoio administrativo e quadros complementares, mas também no quadro de oficiais, passando a receber, em 2003, as primeiras mulheres para o Curso de Formação de Oficiais Aviadores. Com relação à Marinha, a Lei n. 9.519/97 permitiu a participação feminina na prestação de serviços em diversas áreas (engenharia, saúde, intendência, quadro auxiliar da Armada, entre outras).

A Tabela 3 traz a distribuição de homens e mulheres nos grandes grupos de ocupações em 2004 e 2015. Essas são, de acordo com as equações (1) a (4) apresentadas anteriormente, as informações necessárias para o cálculo das medidas de segregação segundo grupamentos ocupacionais, discutidas na próxima seção. 
TABELA 3

Distribuição de mulheres e homens ocupados, segundo grandes grupos ocupacionais Brasil - 2004-2015

\begin{tabular}{|c|c|c|c|c|}
\hline \multirow[t]{2}{*}{ Grandes grupos ocupacionais } & \multicolumn{2}{|c|}{2004} & \multicolumn{2}{|c|}{2015} \\
\hline & $m_{j}$ & $h_{j}$ & $m_{j}$ & $h_{j}$ \\
\hline Dirigentes em geral & 3,90 & 5,45 & 4,31 & 5,43 \\
\hline Profissionais das ciências e das artes & 8,53 & 4,20 & 14,23 & 6,55 \\
\hline Técnicos de nível médio & 7,81 & 6,47 & 7,38 & 7,01 \\
\hline Trabalhadores de serviços administrativos & 11,40 & 5,75 & 14,03 & 6,01 \\
\hline Trab. dos serviços, vendedores e prestadores de serviços do comércio & 42,96 & 19,95 & 42,96 & 20,31 \\
\hline Trabalhadores agrícolas & 16,14 & 24,51 & 9,61 & 17,20 \\
\hline $\begin{array}{l}\text { Trab. da produção de bens e serviços industriais, reparação e } \\
\text { manutenção }\end{array}$ & 9,17 & 32,42 & 7,30 & 36,08 \\
\hline Membros das Forças Armadas e auxiliares & 0,09 & 1,26 & 0,19 & 1,40 \\
\hline Total & 100,00 & 100,00 & 100,00 & 100,00 \\
\hline
\end{tabular}

Fonte: PNAD/IBGE 2004-2015. Elaboração dos autores.

Conforme se vê, o grupamento ocupacional que mais absorve a mão de obra feminina é o dos trabalhadores dos serviços, vendedores e prestadores de serviços do comércio. Reduto histórico do emprego feminino, esse grupo agrega aproximadamente $43 \%$ das mulheres ocupadas - proporção que se conservou entre 2004 e 2015. Em segundo lugar situava-se, em 2004, o grupo dos trabalhadores agrícolas. Entretanto, esse segmento perdeu importância em 2015 - fato também observado para os homens -, o que é explicado pela intensa mecanização do setor agropecuário ao longo desses 11 anos de análise. Excluídas as Forças Armadas, os profissionais das ciências e das artes são a categoria em que a participação do emprego feminino mais cresceu entre 2004 e 2015, passando a absorver $14,2 \%$ das trabalhadoras e a assumir a segunda colocação no ranking das ocupações femininas, praticamente empatada com trabalhadores de serviços administrativos.

Em se tratando dos homens, o grupamento de maior importância é o dos trabalhadores da produção de bens e serviços industriais, reparação e manutenção, concentrando ao redor de $1 / 3$ da mão de obra masculina. Em segundo lugar encontravam-se, em 2015, os trabalhadores dos serviços, vendedores e prestadores de serviços do comércio, seguidos pelos trabalhadores agrícolas. Tal como no caso das mulheres, este último foi o grupamento que mais perdeu importância na estrutura de emprego masculino no período analisado. Em contraste, os profissionais das ciências e das artes foram a categoria que mais ganhou participação.

\section{Evolução da segregação segundo os grandes grupos ocupacionais}

Analisa-se, aqui, a evolução da segregação entre os grandes grupos ocupacionais (um dígito) da CBO-Domiciliar. Dessa maneira, as medidas de segregação são obtidas considerando-se oito grupos de ocupações $U=8$ nas eqs. (1), (2) e (3)]. Em se tratando da medida geral de segregação em sua forma de decomposição $U=48$ e $n_{g}=8$ na eq. (4)], os valores apresentados nesta seção referem-se à segregação aferida entre os grupos (ou seja, o segundo termo do lado direito da eq. 4). Além do cálculo das medidas de segregação, também são obtidas as curvas de segregação segundo os grandes grupos ocupacionais. 
A comparação da posição de curvas de segregação em momentos distintos no tempo permite avaliar se houve aumento ou diminuição da segregação. Essa análise é similar à realizada por Rothschild e Stiglitz (1970) e Dasgupta, Sen e Starrett (1973) ao abordarem o conceito de dominância de Lorenz, tendo sido adaptada por Hutchens (1991) para o caso da segregação. Segundo este autor, ao se compararem curvas de segregação em instantes diferentes - por exemplo, em $t$ e $t+1-$, se os pontos da curva em $t+1$ estiverem acima ou coincidirem com aqueles da curva referente a $t$ - mas nunca posicionados abaixo desta -, diz-se que a curva de segregação em $t+1$ domina a curva referente a $t$. Isso significa que qualquer medida de segregação que obedeça à propriedade de movimento entre ocupações ${ }^{15}$ indicará diminuição da segregação de $t$ para $t+1$. Essa análise é bastante útil quando não há intersecção das curvas de segregação, pois apresenta um ranking completo da distribuição ocupacional em diferentes anos, independentemente da medida de segregação utilizada (desde que esta atenda à propriedade de movimento entre ocupações).

O Gráfico 2 apresenta as curvas de segregação para o Brasil, em 2004 e 2015. A curva para 2004, em sua parte inicial próxima à origem, situa-se abaixo da curva referente a 2015 , porém a intercepta próximo dos $2 \%$ da participação acumulada dos homens (eixo das abcissas). Desse modo, não é possível afirmar, com base na análise exclusiva das curvas, se a segregação aumentou ou diminuiu no período. Quando as curvas de segregação se cruzam, medidas diferentes podem indicar direções opostas na evolução da segregação. Utilizando a medida geral de segregação como exemplo, Botassio e Hoffmann (2020) concluíram que essa classe de índices, quando assume valores elevados do parâmetro $\varepsilon$, é mais sensível a mudanças em ocupações com poucas mulheres. Por outro lado, para valores baixos de $\varepsilon$, essa medida é mais sensível ao que ocorre em ocupações com poucos homens. Tendo isso em vista, um índice da classe da medida geral de segregação com valor extremamente elevado de $\varepsilon$ indicaria aumento da segregação, ao passo que um índice com valor extremamente baixo de $\varepsilon$ indicaria queda na segregação. Os mesmos autores mostraram, para dados sobre segregação de gênero por setores de atividade econômica no Brasil de 1992 a 2013, que o intervalo de variação de $\varepsilon$ entre 0 e 1,7 permite encontrar conclusões opostas sobre a evolução da segregação no período.

Quando a comparação das curvas de segregação não é conclusiva, a solução adotada é a utilização de medidas de segregação que permitam um ordenamento completo de distribuições. As medidas usuais na literatura são os índices de dissimilaridade e de Gini. Neste trabalho também é calculada a medida geral de segregação com parâmetro $\varepsilon=0$ ( $T$ de Theil), 0,5 e 1 ( $L$ de Theil). ${ }^{16} 0$ Gráfico 3 apresenta a evolução dessas medidas para 0 Brasil, no período de 2004 a 2015.

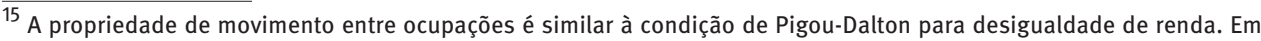
resumo, essa propriedade diz que, se mulheres ocupadas mudam para ocupações que são relativamente ocupadas por mais mulheres, a segregação aumenta (e vice-versa). A propriedade de movimento entre ocupações é exaustivamente analisada por Botassio e Hoffmann (2020).

${ }^{16}$ Tendo em vista a sensibilidade da medida geral de segregação a valores extremos do parâmetro $\varepsilon$, optou-se por limitálo ao intervalo $[0,1]$.
} 
GRÁFICO 2

Curvas de segregação

Brasil - 2004-2015

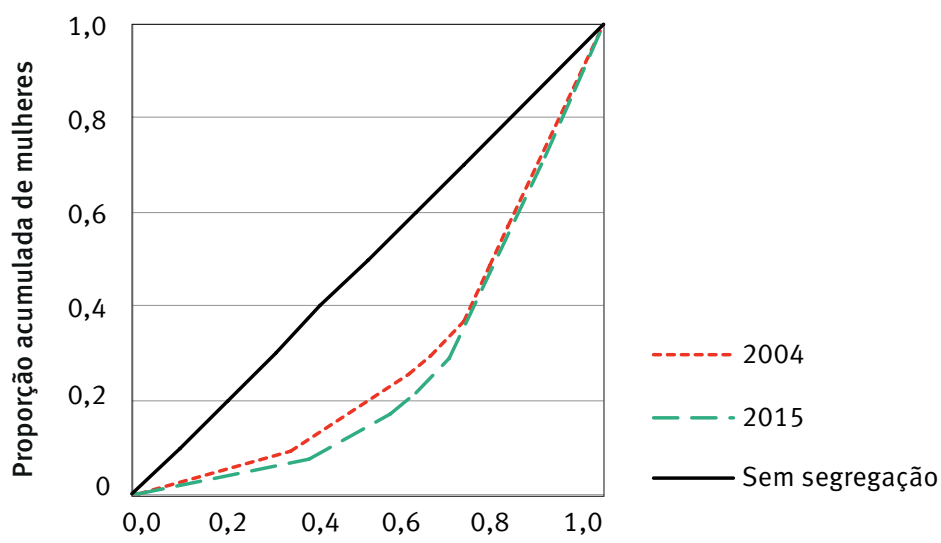

Proporção acumulada de homens

Fonte: PNAD/IBGE 2004-2015. Elaboração dos autores.

GRÁFICO 3

Medidas de segregação ocupacional por sexo, segundo os grandes grupos ocupacionais da CBO-

Domiciliar

Brasil - 2004-2015

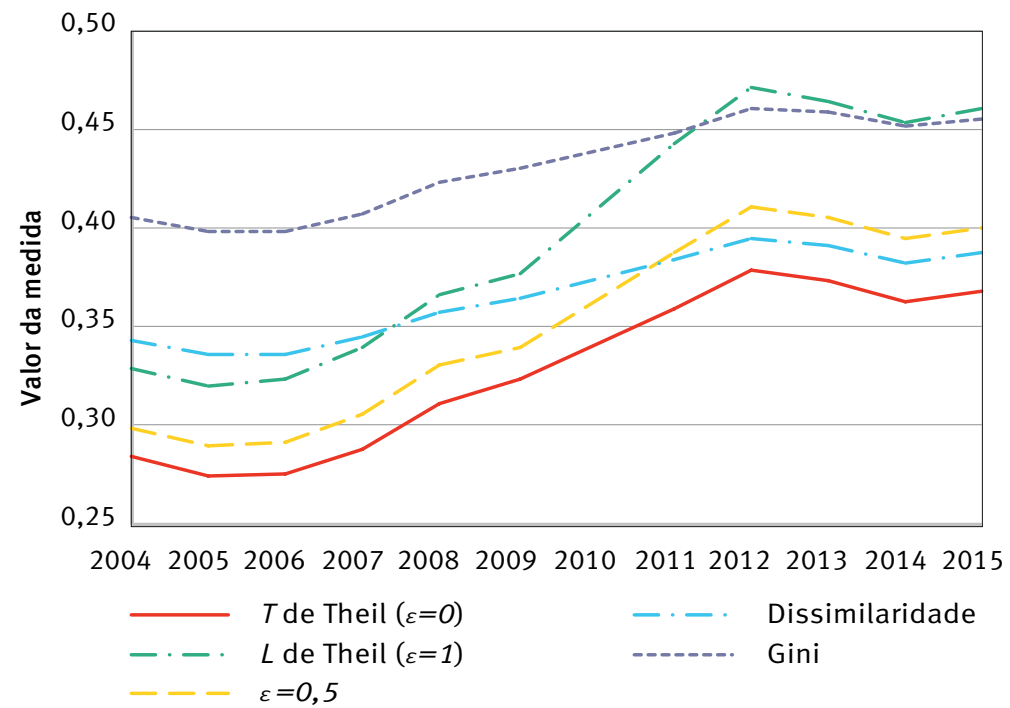

Fonte: PNAD/IBGE 2004-2015. Elaboração dos autores.

Nota: Os valores referentes a 2010 resultam de interpolação linear.

Para todas as medidas utilizadas, verifica-se aumento da segregação entre $2004 \mathrm{e}$ 2015, que varia de $12,2 \%$, no caso do índice de Gini, a $40 \%$, segundo o $L$ de Theil, com valores intermediários para as demais medidas. 
Fracionando o intervalo 2004-2015 em subperíodos, observa-se, entre 2004 e 2006, diminuição da segregação, segundo os índices de Gini, de dissimilaridade e a medida $I_{0,5}$. As medidas $T$ e $L$ de Theil, entretanto, indicam queda na segregação somente entre 2004 e 2005 , com sutil aumento entre 2005 e 2006 . Por outro lado, todas as medidas apontam para o crescimento na segregação de 2006 a 2012 e entre 2014 e 2015 . Além disso, todas mostram redução na segregação entre 2012 e 2014. Independentemente da medida utilizada, há um pico na segregação em 2012. Existe forte correlação linear positiva - sempre superior a 0,99 e estatisticamente significativa - entre todas as medidas, conforme mostra a Tabela 1 do Anexo.

Cabe lembrar que o trabalho mais recente que examina a evolução da segregação ocupacional por sexo no Brasil é o de Salardi (2016), que analisa o intervalo 1995-2006 e conclui que a segregação diminuiu nesse período. Assim, este trabalho corrobora as conclusões da autora até 2006, mas indica inversão na tendência de queda a partir desse ano.

Para verificar a evolução da tendência da segregação no período 2004-2015, pode-se, adicionalmente, ajustar o modelo de regressão linear $\ln \left(\right.$ medid $\left.a_{t}\right)=\alpha+\beta t+\varepsilon_{t}$, em que medid $a_{t}$ é o valor da segregação no ano $t, \alpha$ e $\beta$ são parâmetros e $\varepsilon_{t}$ é um termo de erro estocástico. Nesse modelo, a transformação $\left(e^{\beta}-1\right) .100 \%$ fornece a taxa média anual de crescimento da segregação, segundo a medida utilizada. A Tabela 4 apresenta os resultados dessas regressões, que foram estimadas pelo método de mínimos quadrados.

TABELA 4

Regressão da segregação por sexo entre os grandes grupos ocupacionais, em função de uma tendência linear

Brasil - 2004-2015

\begin{tabular}{lccccc}
\hline & $T$ de Theil & $\boldsymbol{I}_{0,5}$ & $\boldsymbol{L}$ de Theil & $\begin{array}{c}\text { Índice de } \\
\text { dissimilaridade }\end{array}$ & Índice de Gini \\
\hline Tendência & 0,033 & 0,036 & 0,041 & 0,016 & 0,015 \\
& $(0,004)$ & $(0,004)$ & $(0,004)$ & $(0,002)$ & $(0,002)$ \\
$R^{2}$ & 0,8865 & 0,9007 & 0,9101 & 0,8606 & 0,8842 \\
\hline
\end{tabular}

Fonte: PNAD/IBGE 2004-2015. Elaboração dos autores.

Nota: Todas as estimativas são estatisticamente significativas a $0,1 \%$; desvios-padrão robustos entre parênteses; as constantes foram omitidas.

Independentemente da medida utilizada, é possível afirmar, ao nível de significância de $0,1 \%$, que a segregação aumentou entre 2004 e 2015 . 0 coeficiente de determinação do modelo $\left(R^{2}\right)$ indica que a tendência temporal explica entre $86 \%$ (para o índice de dissimilaridade) e $91 \%$ (para o $L$ de Theil) da variabilidade no logaritmo do valor da segregação. As taxas médias anuais de crescimento foram de 3,3\% (para o $L$ de Theil), 3,7\% $\left(I_{0,5}\right), 4,2 \%$ ( $L$ de Theil), 1,6\% (dissimilaridade) e 1,5\% (Gini). 


\section{Evolução da segregação segundo os subgrupos ocupacionais principais}

Nesta subseção a mensuração da segregação é realizada em nível mais desagregado, considerando-se os 48 subgrupos ocupacionais principais (classificação a dois dígitos) da CBO-Domiciliar. 0 Gráfico 4 apresenta a evolução das medidas de segregação no período 2004-2015.

\section{GRÁFICO 4}

Medidas de segregação ocupacional por sexo, segundo os subgrupos ocupacionais principais da CBODomiciliar

Brasil - 2004-2015

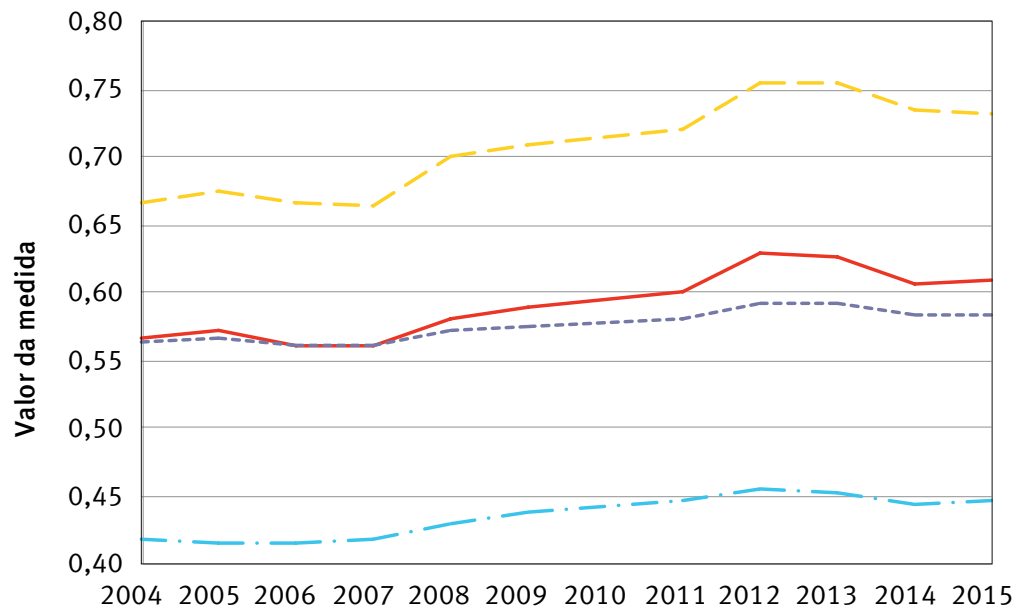

Fonte: PNAD/IBGE 2004-2015. Elaboração dos autores.

Nota: Os valores referentes a 2010 resultam de interpolação linear.

Cabe lembrar que a medida $L$ de Theil $(\varepsilon=1)$ não é definida quando há ao menos uma ocupação sem mulheres, o que ocorre para 2004, 2008 e 2011, ao se considerarem os subgrupos ocupacionais principais. ${ }^{17}$ Por esse motivo, optou-se por não apresentar essa medida no Gráfico 4.

A segregação por sexo aferida ao se considerar a classificação ocupacional a dois dígitos aumentou, entre 2004 e 2015, para todas as medidas utilizadas: 3,6\% para o

\footnotetext{
${ }^{17}$ A amostra de 2004 da PNAD não continha nenhuma mulher no subgrupo dos operadores de instalações de produção e distribuição de energia, utilidades, captação, tratamento e distribuição de água (pertencente ao grande grupo ocupacional de trabalhadores da produção de bens e serviços industriais, de reparação e manutenção). Já em 2008 e 2011, a amostra não trazia mulheres no subgrupo de profissionais policientíficos (do grande grupo profissionais das ciências e das artes). Esse fenômeno reflete um aspecto importante das pesquisas amostrais domiciliares, que deve ser tratado com cautela. Quando há poucas pessoas em uma população com determinada característica, a probabilidade de alguma dessas pessoas ser sorteada para entrevista é pequena. Caso esse evento não ocorra, por exemplo, nenhuma mulher em uma determinada ocupação seja entrevistada pelos agentes da PNAD, as expansões populacionais (para o Brasil) indicarão que não há mulheres nessa ocupação no país (subestimação). Por outro lado, se um número relativamente grande de pessoas em determinada ocupação for entrevistada, essa ocupação poderá ser sobre-estimada na população. Podem-se utilizar os dados da Relação Anual de Informações Sociais (Rais) para auxiliar na interpretação dos resultados, devido ao seu caráter censitário. Em se tratando dos grupos de dirigentes e membros das Forças Armadas e auxiliares, em que a maior parte dos ocupados possui vínculo formal de emprego, a Rais é uma excelente fonte de informação.
} 
índice de Gini; 7,3\% para o índice de dissimilaridade; 7,4\% para o $T$ de Theil; e 9,9\% para a $I_{0,5}$. De modo geral, as medidas apresentaram sutil aumento de 2004 a 2005, seguido de queda de 2005 a 2007, crescimento de 2007 a 2012, estabilidade entre 2012 e 2013 e redução entre 2013 e 2015.

Ao se compararem os valores da segregação quando a classificação ocupacional é considerada a um e a dois dígitos - disponíveis nas Tabelas 2 e 3 do Anexo, respectivamente - constata-se que a segregação é maior ao se incluir um número maior de categorias ocupacionais. Por exemplo, a julgar pelo índice de dissimilaridade, em 2015, 38,7\% das mulheres precisariam mudar de um grande grupo ocupacional predominantemente feminino para outro preponderantemente masculino, a fim de que a segregação segundo essa forma de classificação das ocupações fosse eliminada. Esse percentual eleva-se para $44,7 \%$ ao se considerar a agregação das ocupações em subgrupos ocupacionais principais. Não apenas o índice de dissimilaridade, mas também as demais medidas de segregação calculadas mostram-se sensíveis ao número de categorias analisadas, indicando mais segregação quanto mais desagregados forem os grupos de ocupações. Esse comportamento dos índices de segregação é de conhecimento na literatura (OLIVEIRA, 2003) e pode ser compreendido à luz da equação 4, apresentada anteriormente: em seu lado esquerdo, tem-se a segregação medida quando considerados os dois primeiros dígitos da CBO. $O$ lado direito da igualdade mostra que esse valor resulta da soma da segregação dentro dos grupos e entre os grupos. A segregação entre grupos é aquela quando utilizada a mesma classificação, porém a um dígito, ou seja, menos desagregada. Assim, vê-se que o valor da segregação, quando medida a dois dígitos, corresponde ao valor da segregação medida a um dígito mais a segregação dentro dos grupos ocupacionais a dois dígitos. Esse último componente não pode ser negativo e dificilmente será nulo, dado que é pouco provável que não exista nenhum grau de segregação em quaisquer dos grupos ocupacionais estudados. Assim, por construção, vê-se que a consideração de um maior nível de desagregação na forma de classificação das ocupações nunca reduz o valor da segregação, e muito frequentemente a eleva.

A Tabela 5 mostra os resultados das regressões utilizadas para estimar a taxa média anual de crescimento da segregação, de modo análogo aos resultados da Tabela 4, apresentada anteriormente.

Os resultados mostram que há evidências estatísticas para afirmar, ao nível de significância de $0,1 \%$, que a segregação aumentou no período de 2004 a 2015. Segundo os modelos estimados, as taxas médias anuais de crescimento da segregação situam-se entre $0,5 \%$ (no caso do índice de Gini) e 1,2\% (para a medida $I_{0,5}$ ). Para o $T$ de Theil, essa taxa é de $1 \%$ e, para o índice de dissimilaridade, de 0,9\%. 
TABELA 5

Regressão da segregação por sexo entre os subgrupos ocupacionais principais, em função de uma tendência linear

Brasil - 2004-2015

\begin{tabular}{lcccc}
\hline & $T$ de Theil & $I_{0,5}$ & $\begin{array}{c}\text { Índice de } \\
\text { dissimilaridade }\end{array}$ & Índice de Gini \\
\hline Tendência & 0,010 & 0,012 & 0,009 & 0,005 \\
& $(0,002)$ & $(0,002)$ & $(0,001)$ & $(0,001)$ \\
$R^{2}$ & 0,7652 & 0,8152 & 0,8082 & 0,7812 \\
\hline
\end{tabular}

Fonte: PNAD/IBGE 2004-2015. Elaboração dos autores.

Nota: Todas as estimativas são estatisticamente significativas a $0,1 \%$; desvios-padrão robustos entre parênteses; as constantes foram omitidas.

Diferentes gerações apresentam diferentes comportamentos no mercado de trabalho, em razão dos distintos contextos sociais e momentos históricos em que foram socializadas. Embora estudiosos dos perfis das gerações nem sempre adotem rigorosamente os mesmos períodos para identificá-las, eles não divergem significativamente ao descreverem as características dos indivíduos que as compõem. Estudos em psicologia organizacional têm reunido evidências a respeito das diferenças de comportamento, valores e visões entre as três gerações ativas no mercado de trabalho - referindo-se a elas como boomers, geração X e geração Y ou millennials (WEY SMOLA; SUTTON, 2002; COMAZZETTO et al., 2016). Assim, adotando essa classificação, o Gráfico 5 traz a evolução dos índices de dissimilaridade e de Gini, calculados quando a amostra de trabalhadores é segmentada nessas três coortes de nascimentos: nascidos entre 1946 e 1964 (boomers); entre 1965 e 1980 (geração X); e entre 1981 e 1996 (millennials). Observa-se que, a cada nova geração, o nível de segregação por sexo vivenciado pelos trabalhadores é menor. Entretanto, entre 2004 e 2015 há um aumento no grau de segregação tanto para a geração $X$ como para os millennials. Para os boomers, a tendência é oposta - de redução na segregação -, entretanto, cumpre notar que, em 2004, os primeiros boomers aproximavam-se dos 60 anos de idade e, em 2015, completavam 69 anos. Assim, o período coincide com a paulatina transição dessa geração para a inatividade econômica, com a consequente redução de seu peso na composição da mão de obra. De modo contrário, a participação dos millennials tende a aumentar ao longo do período. 
GRÁFICO 5

Índices de dissimilaridade e de Gini para subgrupos ocupacionais principais da CBO-Domiciliar, segundo coortes de nascimentos

Brasil - 2004-2015
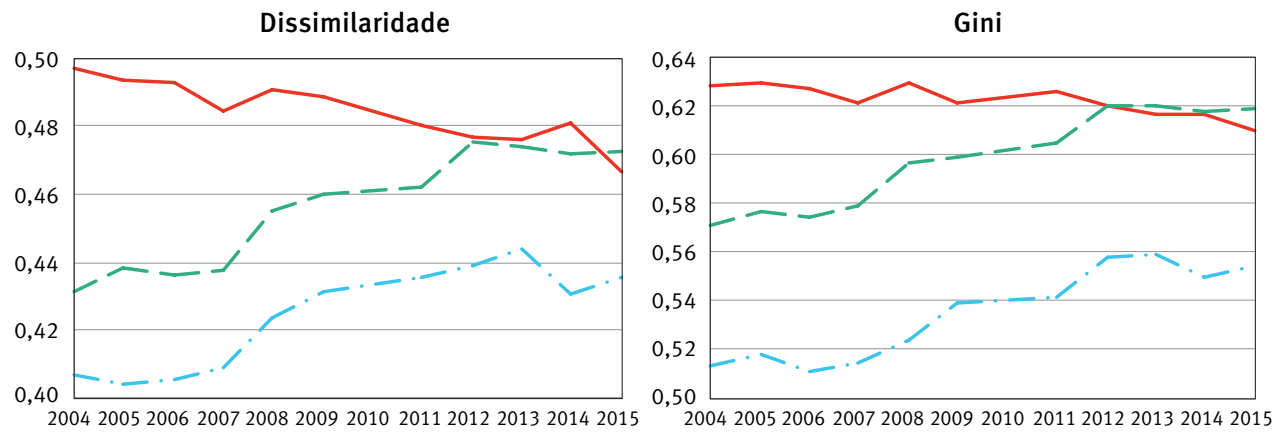

Boomers (1946-1964)

- - Geração X (1965-1980)

- - Milennials (1981-1996)

Fonte: PNAD/IBGE 2004-2015. Elaboração dos autores.

Nota: Os valores referentes a 2010 resultam de interpolação linear.

\section{Decomposição da segregação}

Nesta subseção a segregação total (medida a dois dígitos) é decomposta em duas parcelas: uma referente à segregação entre os oito grandes grupos ocupacionais; e outra que corresponde a uma soma ponderada das medidas de segregação dentro de cada um desses oito grupamentos. Se denotarmos por $B_{\varepsilon}$ a parcela entre grupos dessa decomposição (segundo termo do lado direito da equação 4), sua participação na segregação total é dada por $S_{\varepsilon}=\left(B_{\varepsilon} / I_{\varepsilon}\right) .100 \%$. 0 Gráfico 6 permite verificar a evolução dessa parcela no período 2004-2015.

Como nem o índice de Gini nem o de dissimilaridade são aditivamente decomponíveis, eles não são apresentados no Gráfico 6. Além disso, como a medida $T$ de Theil $(\varepsilon=0)$ não é definida quando existe pelo menos uma ocupação sem homens, e o $L$ de Theil $(\varepsilon=1)$ não é definido quando existe pelo menos uma ocupação sem mulheres, é conveniente utilizar a medida geral com valores de $\varepsilon$ próximos de 0 ou 1, a fim de se obter uma aproximação do comportamento das medidas de Theil quando elas não são definidas. Assim, optou-se por calcular, também, a medida geral de segregação para $\varepsilon=0,1$ e $\varepsilon=0,9$.

Para todas as medidas, há clara tendência linear de crescimento da participação do componente entre grupos na segregação total para o Brasil. 0 menor crescimento foi verificado com o índice $T$ de Theil (20,8\% ou 10,4 p.p.), seguido pela medida $I_{0,1}(21 \%$ ou 10,4 p.p.), pela $I_{0,5}$ (22\% ou 9,9 p.p.) e pela $I_{0,9}$ (23,2\% ou 8,3 p.p.). ${ }^{18}$ Esse resultado relaciona-se aos obtidos nas seções anteriores, isto é, ao fato de a segregação medida a um dígito ter crescido mais rapidamente do que seu valor a dois dígitos, conforme se depreende ao se compararem as taxas médias anuais de crescimento apresentadas nas

\footnotetext{
${ }^{18}$ Note que há correlação positiva entre o valor de $\varepsilon$ e a intensidade do crescimento da participação do componente entre grupos na segregação total para o Brasil.
} 
Tabelas 4 e 5 . Como a segregação medida a um dígito corresponde ao componente entre grupos da segregação medida a dois dígitos, isso fez quem com que aquela ampliasse sua participação no valor total desta.

\section{GRÁFICO 6}

Participação da segregação entre grandes grupos no total da segregação

$\%$

Brasil - 2004-2015

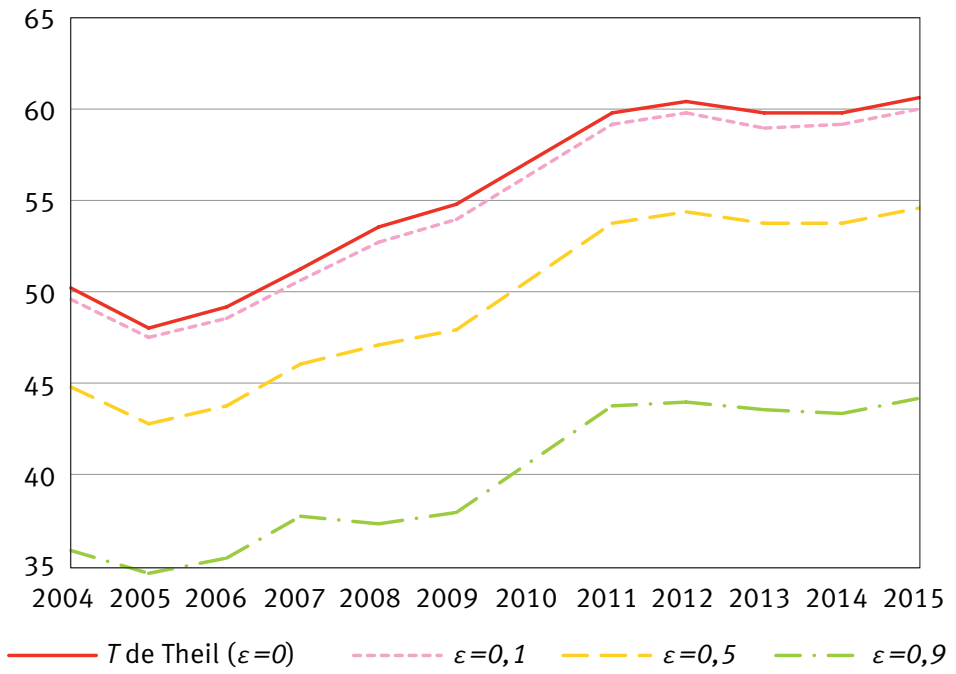

Fonte: PNAD/IBGE 2004-2015. Elaboração dos autores.

Nota: Os valores referentes a 2010 resultam de interpolação linear.

A Tabela 6 apresenta regressões de tendência da participação do componente entre grupos na segregação total. 0 modelo estimado é $\ln \left(S_{\varepsilon t}\right)=\alpha+\beta t+\varepsilon_{t}$, em que $S_{\varepsilon t}$ é a participação da parcela entre grupos na segregação total calculada segundo a medida $I_{\varepsilon}$ no instante $t$.

TABELA 6

Regressão da participação da segregação entre grupos no total da segregação Brasil - 2004-2015

\begin{tabular}{lcccc}
\hline & \multicolumn{5}{c}{$\boldsymbol{\varepsilon}$} \\
\cline { 2 - 5 } & $\mathbf{0}$ & $\mathbf{0 , 1}$ & $\mathbf{0 , 5}$ & $\mathbf{0 , 9}$ \\
\hline Tendência & 0,023 & 0,023 & 0,024 & 0,025 \\
& $(0,003)$ & $(0,003)$ & $(0,003)$ & $(0,003)$ \\
$R^{2}$ & 0,9003 & 0,9020 & 0,9014 & 0,8849 \\
\hline
\end{tabular}

Fonte: PNAD/IBGE 2004-2015. Elaboração dos autores.

Nota: Todas as estimativas são estatisticamente significativas a $0,1 \%$; desvios-padrão robustos entre parênteses; as constantes foram omitidas.

Considerando todas as medidas, há evidências estatísticas a 0,1\% para afirmar que a participação da parcela entre grupos na segregação total aumentou entre 2004 e 2015. Como foi verificado crescimento da segregação total (medida a dois dígitos) nesse período, isso significa que tal aumento foi impulsionado pela segregação entre grupos, tendo o 
componente dentro dos grupos decrescido. Assim, a segregação tem diminuído em grupos mais homogêneos (criados a partir da característica de similaridade), mas crescido substancialmente entre grupos que apresentam ocupações mais heterogêneas. As taxas de crescimento médias anuais da participação da parcela entre grupos na segregação total foram 2,3\% para o $T$ de Theil e a $I_{0,1}, 2,45 \%$ para a $I_{0,5}$ e $2,5 \%$ para a $I_{0,9}$.

\section{Conclusões}

Neste trabalho foram analisadas as características da distribuição ocupacional por sexo no Brasil e sua evolução no período 2004-2015. Verificou-se que o grau de segregação ocupacional permanece em um patamar elevado no país: a julgar pelo índice de dissimilaridade calculado com base na CBO-Domiciliar a dois dígitos, 44,7\% das mulheres precisariam mudar de um subgrupo ocupacional predominantemente feminino para outro preponderantemente masculino, a fim de que a segregação fosse eliminada. Os resultados indicam, ainda, que houve aumento na segregação entre 2004 e 2015, o qual oscilou entre $3,6 \%$ e $9,9 \%$, dependendo da medida utilizada.

Conforme visto, os 48 subgrupos ocupacionais principais (classificação a dois dígitos) da $\mathrm{CBO}$-Domiciliar podem ser organizados em oito grandes grupos, correspondentes à mesma classificação a um dígito. A medida geral de segregação $\left(I_{\varepsilon}\right)$ permite que a segregação medida a dois dígitos seja decomposta em duas parcelas: uma referente à segregação entre os oito grandes grupos ocupacionais - equivalente ao valor de $I_{\varepsilon}$ quando a mensuração é feita ao nível mais agregado, a um dígito -; e outra que corresponde a uma soma ponderada das medidas de segregação dentro de cada um dos oito grupamentos. Essa decomposição mostrou que o aumento da segregação entre 2004 e 2015 deveu-se ao crescimento da segregação entre os oito grandes grupos. Essa parcela passou a responder, em 2015, por cerca de $60 \%$ de toda a segregação observada. Isso implica dizer que os grandes grupos ocupacionais da CBO tornaram-se menos integrados.

Vale notar que os resultados encontrados contrastam com a tendência de queda na segregação relatada na literatura referente a anos anteriores ao período estudado. Assim, depreende-se que, quando o aumento na participação das mulheres no mercado de trabalho era vigoroso - particularmente nas décadas de 1980 e 1990 -, a segregação diminuía. Porém, quando a participação feminina começou a se estabilizar, nos anos 2000, a tendência de queda na segregação passou a apresentar seus primeiros sinais de esgotamento. Esse resultado é preocupante, pois a literatura aponta que a segregação ocupacional é um dos principais determinantes do hiato salarial de gênero no mercado de trabalho brasileiro, tendo em vista que as ocupações nas quais as mulheres se concentram são, em média, menos valorizadas socialmente e pior remuneradas. As tendências recentes de recrudescimento no grau de segregação ocupacional podem ajudar a compreender por que a desigualdade de rendimento por sexo resiste a declinar no Brasil, ainda que as mulheres acumulem progressivamente maior número de anos de escolaridade do que os homens. Estudos futuros 
podem ajudar a responder se um fator - aumento da segregação ocupacional - estaria compensando o outro - ampliação do hiato educacional em favor das mulheres.

Observou-se, ainda, que, entre 2004 e 2015, as mulheres elevaram sua participação tanto entre os profissionais das ciências e das artes e os dirigentes em geral, como entre os trabalhadores dos serviços, vendedores e prestadores de serviços do comércio. Esses resultados endossam a hipótese de dualização do emprego feminino, tendo em vista que, ao mesmo tempo que as mulheres avançam em ocupações de maior prestígio e complexidade, elas conservam sua participação em redutos históricos do emprego feminino, nos quais as condições de trabalho permanecem em grande medida precárias.

A segregação ocupacional por sexo é, em última instância, um reflexo da interiorização das normas de gênero vivenciadas por homens e mulheres, pois os papéis sociais vistos como femininos ou masculinos influenciam as escolhas profissionais dos trabalhadores e 0 tratamento que eles recebem dos empregadores. As implicações dos resultados encontrados nesta pesquisa, em termos de políticas públicas, repousam, portanto, na difícil tarefa de superação da divisão sexual do trabalho. É preciso incentivar a participação feminina em carreiras predominantemente masculinas, e vice-versa, desconstruindo o estereótipo de que o trabalho de cuidado - presente em ocupações como as de professoras, enfermeiras, babás - é eminentemente feminino. Ao mesmo tempo, é necessário promover políticas que incentivem a divisão equitativa das responsabilidades domésticas e familiares entre homens e mulheres e reforçar aquelas que possam auxiliar as mulheres a ampliarem seu tempo de permanência no mercado de trabalho - como maior oferta de vagas em creches e pré-escolas públicas -, a fim de que as escolhas profissionais femininas sejam pautadas em suas reais preferências individuais, em vez de buscarem prioritariamente a conciliação de sua dupla jornada de trabalho.

\section{Referências}

ANKER, R. Theories of occupational segregation by sex: an overview. International Labour Review, v. 136, n. 3, p. 315-339, 1997.

ARAÚJO, V. F.; RIBEIRO, E. P. Diferenciais de salários por gênero no Brasil: uma análise regional. Porto Alegre: PPGE/UFRGS, 2001. (Texto para Discussão n. 11). Disponivel em: https://www. ufrgs.br/ppge/wp-content/themes/PPGE/page/textos-para-discussao/pcientifica/2001_11. pdf. Acesso em: 13 nov. 2019.

BARROS, R. P.; MACHADO, A. F.; MENDONÇA, R. S. P. A desigualdade da pobreza: estratégias ocupacionais e diferenciais por gênero. Rio de Janeiro: Ipea, jan. 1997. (Texto para Discussão, n. 453). Disponível em: http://www.ipea.gov.br/portal/images/stories/PDFs/TDs/td_0453.pdf. Acesso em: 14 nov. 2019.

BECKER, G. The economics of discrimination. Chicago, IL: Chicago University Press, 1957.

BELTRÃO, K. I.; ALVES, J. E. A reversão do hiato de gênero na educação brasileira no século XX. Cadernos de Pesquisa, São Paulo, v. 39, n. 136, p. 125-156, 2009. 
BOTASSIO, D. C. Segregação e desigualdade: analogia na mensuração e análise da segregação por gênero em setores de atividade no Brasil. 2017. Dissertação (Mestrado em Economia Aplicada) - Escola Superior de Agricultura Luiz de Queiroz, Universidade de São Paulo, Piracicaba, 2017.

BOTASSIO, D. C.; HOFFMANN, R. Measuring gender segregation: sensitivity to movements and to an increase in one category. Economic Theory Bulletin, v. 8, n. 1, p. 25-47, 2020.

BRUSCHINI, C. Trabalho feminino: trajetória de um tema, perspectiva para o futuro. Revista Estudos Feministas, v. 2, n. 3, p. 17-32, 1994.

BRUSCHINI, C.; LOMBARDI, M. R. O trabalho da mulher brasileira nos primeiros anos da década de noventa. In: ENCONTRO NACIONAL DE ESTUDOS POPULACIONAIS, 10. Anais [...]. Caxambu: Abep, 1996. v. 1, p. 483-516.

BRUSCHINI, C.; LOMBARDI, M. R. Mulheres e homens no mercado de trabalho brasileiro: um retrato dos anos 1990. In: MARUANI, M.; HIRATA, H. As novas fronteiras da desigualdade. Homens e mulheres no mercado de trabalho. São Paulo: Editora Senac, 2003. p. 323-361.

COMAZZETTO, L. R. et al. A geração $Y$ no mercado de trabalho: um estudo comparativo entre gerações. Psicologia: Ciência e Profissão, Brasília, v. 36, n. 1, p. 145-157, mar. 2016.

COSTA, L. Aumento da participação feminina: uma tentativa de explicação. In: ENCONTRO NACIONAL DE ESTUDOS POPULACIONAIS, 7. Anais [...]. Caxambu: Abep, 1990. v. 2, p. 231-243.

DASGUPTA, P.; SEN, A.; STARRETT, D. Notes on the measurement of inequality. Journal of Economic Theory, v. 6, n. 2, p. 180-187, Apr. 1973.

DEGRAFF, D. S.; ANKER, R. Gênero, mercados de trabalho e o trabalho das mulheres. In: PINNELLI, A. (org.). Gênero nos estudos de população. Campinas: Associação Brasileira de Estudos Populacionais (Abep), 2004.

DUNCAN, O. D.; DUNCAN, B. A methodological analysis of segregation indexes. American Sociological Review, v. 20, n. 2, p. 210-217, Apr. 1955.

GROSS, E. Plus ça change...? The sexual structure of occupations over time. Social Problems, v. 16, n. 2, p. 198-208, 1968.

HAKIM, C. Key issues in women's work: female heterogeneity and the polarization of women's employment. London, Atlantic Highlands: Athlone, 1996.

HIRATA, H.; KERGOAT, D. Novas configurações da divisão sexual do trabalho. Cadernos de Pesquisa, v. 37, n. 132, p. 595-609, set./dez. 2007.

HIRATA, H.; KERGOAT, D. Divisão sexual do trabalho profissional e doméstico: Brasil, França, Japão. In: COSTA, A. O. et al. (org.). Mercado de trabalho e gênero: comparações internacionais. Rio de Janeiro: Editora FGV, 2008. p. 263-278.

HOFFMANN, R.; BOTASSIO, D. C.; JESUS, J. G. Distribuição de renda: medidas de desigualdade, pobreza, concentração, segregação e polarização. São Paulo: Editora da Universidade de São Paulo, 2019.

HUTCHENS, R. M. Segregation curves, Lorenz curves, and inequality in the distribution of people across occupations. Mathematical Social Science, v. 21, n. 1, p. 31-51, Feb. 1991.

HUTCHENS, R. Numerical measures of segregation: desirable properties and their implications. Mathematical Social Sciences, v. 42, n. 1, p. 13-29, Jul. 2001.

HUTCHENS, R. One measure of segregation. International Economic Review, v. 45, n. 2, p. 555-578, May 2004. 
JAHN, J.; SCHMID, C. F.; SCHRAG, C. The measurement of ecological segregation. American Sociological Review, v. 12, n. 3, p. 293-303, jun. 1947.

KASSOUF, A. L. Wage gender discrimination and segmentation in the Brazilian labor market. Economia Aplicada, v. 2, n. 2, p. 243-269, 1998.

KERGOAT, D. Divisão sexual do trabalho e relações sociais de sexo. In: HIRATA, H. et al. (org.). Dicionário crítico do feminismo. São Paulo: Editora da Unesp, 2009. p. 67-75.

KING, M. C. Occupational segregation by race and sex in Brazil, 1989-2001. The Review of Black Political Economy, v. 36, n. 2, p. 113-125, 2009.

MADALOZZO, R. Occupational segregation and the gender wage gap in Brazil: an empirical analysis. Economia Aplicada, v. 14, n. 2, p. 147-168, 2010.

MORA, R.; RUIZ-CASTILLO, J. Additively decomposable segregation indexes. The case of gender segregation by occupations and human capital levels in Spain. The Journal of Economic Inequality, v. 1, n. 2, 2003.

OLIVEIRA, A. M. H. Occupational gender segregation and effects on wages in Brazil. In: GENERAL POPULATION CONFERENCE, 24. Proceeding [...]. Salvador: International Union for the Scientific Study of Population, 2001, Disponível em: http://archive.iussp.org/Brazil2001/s30/S38_03_ Oliveira.pdf.

OLIVEIRA, A. M. H. C. A segregação ocupacional por gênero e seus efeitos sobre os salários no Brasil. In: WAJNMAN, S.; MACHADO, A. F. (org.). Mercado de trabalho: uma análise a partir das pesquisas domiciliares no Brasil. Belo Horizonte: Editora UFMG, 2003. p. 121-149.

OMETTO, A. M. H.; HOFFMANN, R.; ALVES, M. C. A segregação por gênero no mercado de trabalho nos estados de São Paulo e Pernambuco. Economia Aplicada, v. 1, n. 3, p. 397-423, 1997.

OMETTO, A. M. H.; HOFFMANN, R.; ALVES, M. C. Participação da mulher no mercado de trabalho: discriminação em Pernambuco e em São Paulo. Revista Brasileira de Economia, Rio de Janeiro, v. 53, n. 3, p. 287-322, jul./set. 1999.

OPPENHEIMER, V. K. The female force in the United States: demographic and economic factors governing its growth and changing composition. Berkeley: University of California Press, 1970.

REIS, M.; AGUAS, M. Duração do desemprego e transições para o emprego formal, a inatividade e a informalidade. Economia Aplicada, v. 18, n. 1, p. 35-50, jan./mar. 2014.

REIS, M. Uma análise da transição dos jovens para o primeiro emprego no Brasil. Revista Brasileira de Economia, v. 69, n. 1, p. 125-143, jan./mar. 2015.

RIBEIRO, R.; ARAÚJO, G. S. Segregação ocupacional no mercado de trabalho segundo cor e escolaridade no Brasil contemporâneo. Nova Economia, v. 26, n. 1, p. 147-177, 2016.

ROTHSCHILD, M.; STIGLITZ, J. E. Increasing risk I: a definition. Journal of Economic Theory, v. 2, n. 3, p. 225-243, set. 1970 .

SALARDI, P. The evolution of gender and racial occupational segregation across formal and non-formal labor markets in Brazil, 1987 to 2006. The Review of Income and Wealth, v. 62, n. S1, p. S68-S89, ago. 2016.

SALAS, C.; LEITE, M. Segregación Sectorial por Género: una comparación Brasil-México. Cadernos PROLAM/USP, ano 7, v. 2, p. 241-259, 2007.

SCORZAFAVE, L. G.; MENEZES-FILHO, N. A. Participação feminina no mercado de trabalho brasileiro: evolução e determinantes. Pesquisa e Planejamento Econômico, v. 31, n. 3, p. 441-478, 2001. 
SOARES, S.; IZAKI, R. S. A participação feminina no mercado de trabalho. Rio de Janeiro: Ipea, dez. 2002. (Texto para Discussão, n. 923). Disponível em: http://www.ipea.gov.br/portal/images/ stories/PDFs/TDs/td_0923.pdf. Acesso em: 14 nov. 2019.

WAJNMAN, S.; QUEIROZ, B.; LIBERATO, V. O crescimento da atividade feminina nos anos noventa no Brasil. In: ENCONTRO NACIONAL DE ESTUDOS POPULACIONAIS, 11. Anais [...]. Caxambu: Abep, 1998. v. 2, p. 2429-2454.

WEY SMOLA, K.; SUTTON, C. D. Generational differences: revisiting generational work values for the new millennium. Journal of Organizational Behavior, v. 23, n. 4, p. 363-382, 2002.

\title{
Sobre os autores
}

Diego Camargo Botassio é mestre em Economia Aplicada pela Escola Superior de Agricultura "Luiz de Queiroz" (Esalq/USP) e bacharel em Ciências Econômicas pela Universidade Federal da Integração Latino-Americana (Unila). Professor assistente de Teoria Econômica na Universidade Estadual de Maringá (UEM).

Daniela Verzola Vaz é doutora e mestre em Economia pela Universidade Estadual de Campinas (Unicamp). Professora adjunta do Departamento de Economia da Universidade Federal de São Paulo (Unifesp).

\section{Endereço para correspondência}

\author{
Diego Camargo Botassio \\ Av. Colombo, 5790 - Bloco C34 \\ 87020-110 - Maringá-PR, Brasil \\ Daniela Verzola Vaz \\ Universidade Federal de São Paulo, Escola Paulista de Política, Economia e Negócios \\ Rua Angélica, 100 - Jd. das Flores \\ 06110-295 - Osasco-SP, Brasil
}

\begin{abstract}
Occupational gender segregation in the Brazilian labor market: a decomposition analysis for the period 2004-2015

This article analyzes the evolution of occupational gender segregation in the Brazilian labor market from 2004 to 2015. Segregation is measured with traditional indicators, such as the dissimilarity and Gini indices, and also using the set of additively decomposable measures proposed by Hutchens (2004), which allows to separate segregation into two parts: one referring to segregation between large occupational groups (1-digit occupational classification), and the other one corresponding to a weighted sum of segregation levels within these groups. Our findings indicate that segregation increased between 2004 and 2015, reversing the downward trend reported in the literature for the period before 2004. The decomposition analysis indicates that this increase has been mainly driven by segregation among broadly defined occupational groups, i.e., across groups entailing very different tasks. We conclude that, as the female labor force participation rate stabilizes, the integration of occupations according to sex may have reached its limit.
\end{abstract}

Keywords: Labor market. Occupational gender segregation. Brazil. 


\section{Resumen}

Segregación ocupacional por sexo en el mercado laboral brasileño: un análisis de descomposición para el período 2004-2015

Este artículo analiza la evolución de la segregación ocupacional por sexo en el mercado laboral brasileño entre 2004 y 2015. La segregación se mide con indicadores tradicionales como los índices de disimilitud y de Gini, y también utilizando la clase de medidas aditivamente descomponibles propuestas por Hutchens (2004), que permiten separar la segregación en dos partes: una que refiere a la segregación entre grandes grupos ocupacionales (clasificación ocupacional de un dígito) y otra que corresponde a una suma ponderada de los niveles de segregación dentro de estos grupos. Los resultados indican que la segregación aumentó entre 2004 y 2015, revirtiendo la tendencia a la baja reportada en la literatura para el período anterior a 2004. El análisis de descomposición indica que este aumento ha sido impulsado principalmente por la segregación medida entre los grandes grupos ocupacionales, es decir, entre grupos que agregan tareas muy distintas. Concluimos que, a medida que la tasa de participación femenina en la fuerza laboral se estabiliza, la integración de ocupaciones según sexo puede haber alcanzado su límite.

Palabras clave: Mercado de trabajo. Segregación ocupacional por sexo. Brasil.

Recebido para publicação em 17/02/2020

Aceito para publicação em 06/09/2020 


\section{Anexo}

TABELA 1

Coeficiente de correlação linear entre as medidas de segregação por grandes grupos ocupacionais Brasil - 2004-2015

\begin{tabular}{|c|c|c|c|c|c|}
\hline & $\begin{array}{c}\text { Índice de } \\
\text { dissimilaridade }\end{array}$ & $\begin{array}{c}\text { Índice de } \\
\text { Gini }\end{array}$ & $T$ de Theil & $I_{0,5}$ & $L$ de Theil \\
\hline Índice de dissimilaridade & 1,000 & & & & \\
\hline Índice de Gini & 0,999 & 1,000 & & & \\
\hline$T$ de Theil & 0,999 & 0,999 & 1,000 & & \\
\hline$I_{0,5}$ & 0,996 & 0,997 & 0,999 & 1,000 & \\
\hline$L$ de Theil & 0,992 & 0,993 & 0,997 & 0,999 & 1,000 \\
\hline
\end{tabular}

Fonte: PNAD/IBGE 2004-2015. Elaboração dos autores.

Nota: Todas as correlações são estatisticamente significativas a $0,1 \%$.

TABELA 2

Medidas de segregação considerando oito grandes grupos ocupacionais Brasil - 2004-2015

\begin{tabular}{cccccccc}
\hline Anos & $T$ & $I_{0,1}$ & $I_{0,5}$ & $I_{0,9}$ & $\boldsymbol{L}$ & $\boldsymbol{D}$ & $\boldsymbol{G}$ \\
\hline 2004 & 0,284 & 0,286 & 0,298 & 0,321 & 0,329 & 0,343 & 0,405 \\
2005 & 0,275 & 0,277 & 0,289 & 0,312 & 0,319 & 0,335 & 0,398 \\
2006 & 0,276 & 0,278 & 0,292 & 0,316 & 0,324 & 0,336 & 0,399 \\
2007 & 0,288 & 0,291 & 0,306 & 0,331 & 0,340 & 0,344 & 0,408 \\
2008 & 0,312 & 0,314 & 0,330 & 0,358 & 0,367 & 0,358 & 0,423 \\
2009 & 0,323 & 0,325 & 0,341 & 0,368 & 0,377 & 0,364 & 0,430 \\
2011 & 0,360 & 0,363 & 0,388 & 0,430 & 0,443 & 0,384 & 0,448 \\
2012 & 0,380 & 0,384 & 0,410 & 0,456 & 0,471 & 0,395 & 0,461 \\
2013 & 0,374 & 0,379 & 0,405 & 0,450 & 0,464 & 0,391 & 0,459 \\
2014 & 0,363 & 0,368 & 0,395 & 0,440 & 0,454 & 0,383 & 0,452 \\
2015 & 0,369 & 0,373 & 0,400 & 0,445 & 0,460 & 0,387 & 0,455 \\
\hline
\end{tabular}

Fonte: PNAD/IBGE 2004-2015. Elaboração dos autores.

TABELA 3

Medidas de segregação considerando 48 subgrupos ocupacionais principais Brasil - 2004-2015

\begin{tabular}{cccccccc}
\hline Anos & $T$ & $I_{0,1}$ & $I_{0,5}$ & $I_{0,9}$ & $L$ & $\boldsymbol{D}$ & $\boldsymbol{G}$ \\
\hline 2004 & 0,566 & 0,577 & 0,666 & 0,893 & - & 0,417 & 0,564 \\
2005 & 0,571 & 0,582 & 0,675 & 0,899 & 0,993 & 0,416 & 0,565 \\
2006 & 0,561 & 0,572 & 0,665 & 0,890 & 0,984 & 0,414 & 0,561 \\
2007 & 0,561 & 0,572 & 0,664 & 0,876 & 0,962 & 0,417 & 0,561 \\
2008 & 0,582 & 0,595 & 0,700 & 0,959 & - & 0,430 & 0,572 \\
2009 & 0,589 & 0,603 & 0,709 & 0,967 & 1,077 & 0,439 & 0,576 \\
2011 & 0,602 & 0,615 & 0,721 & 0,981 & - & 0,447 & 0,582 \\
2012 & 0,628 & 0,642 & 0,754 & 1,032 & 1,151 & 0,455 & 0,593 \\
2013 & 0,627 & 0,641 & 0,754 & 1,033 & 1,151 & 0,452 & 0,592 \\
2014 & 0,608 & 0,622 & 0,734 & 1,014 & 1,136 & 0,443 & 0,583 \\
2015 & 0,608 & 0,622 & 0,732 & 1,005 & 1,121 & 0,447 & 0,585 \\
\hline
\end{tabular}

Fonte: PNAD/IBGE 2004-2015. Elaboração dos autores. 
QUADRO 1

Classificação dos grandes grupos e subgrupos ocupacionais

\begin{tabular}{|c|c|c|}
\hline Grupo & Subgrupo & Titulação \\
\hline \multirow[t]{4}{*}{1} & & Dirigentes em geral \\
\hline & 11 & Membros superiores e dirigentes do poder público \\
\hline & 12 & Dirigentes de empresas e organizações (exceto de interesse público) \\
\hline & 13 & Gerentes \\
\hline \multirow[t]{8}{*}{2} & & Profissionais das ciências e das artes \\
\hline & 20 & Profissionais policientíficos \\
\hline & 21 & Profissionais das ciências exatas, físicas e da engenharia \\
\hline & 22 & Profissionais das ciências biológicas, da saúde e afins \\
\hline & 23 & Profissionais do ensino (com formação de nível superior) \\
\hline & 24 & Profissionais das ciências jurídicas \\
\hline & 25 & Profissionais das ciências sociais e humanas \\
\hline & 26 & Comunicadores, artistas e religiosos \\
\hline \multirow[t]{9}{*}{3} & & Técnicos de nível médio \\
\hline & 30 & Técnicos polivalentes \\
\hline & 31 & Técnicos de nível médio das ciências físicas, químicas, engenharia e afins \\
\hline & 32 & Técnicos de nível médio das ciências biológicas, bioquímicas, da saúde e afins \\
\hline & 33 & Professores leigos e de nível médio \\
\hline & 34 & Técnicos de nível médio em serviços de transportes \\
\hline & 35 & Técnicos de nível médio nas ciências administrativas \\
\hline & 37 & Técnicos em nível médio dos serviços culturais, das comunicações e dos desportos \\
\hline & 39 & Outros técnicos de nível médio \\
\hline \multirow[t]{3}{*}{4} & & Trabalhadores de serviços administrativos \\
\hline & 41 & Escriturários \\
\hline & 42 & Trabalhadores de atendimento ao público \\
\hline \multirow[t]{3}{*}{5} & & Trabalhadores dos serviços, vendedores do comércio \\
\hline & 51 & Trabalhadores dos serviços \\
\hline & 52 & Vendedores e prestadores de serviços do comércio \\
\hline \multirow[t]{5}{*}{6} & & Trabalhadores agrícolas \\
\hline & 61 & Produtores na exploração agropecuária \\
\hline & 62 & Trabalhadores na exploração agropecuária \\
\hline & 63 & Pescadores, caçadores e extrativistas florestais \\
\hline & 64 & Trabalhador da mecanização agropecuária e florestal \\
\hline \multirow[t]{12}{*}{$7 / 8 / 9$} & & Trabalhadores da produção de bens e serviços industriais, reparação e manutenção \\
\hline & 71 & Trabalhadores da indústria extrativa e da construção civil \\
\hline & 72 & Trabalhadores da transformação de metais e de compósitos \\
\hline & 73 & Trabalhadores da fabricação e instalação eletroeletrônica \\
\hline & 74 & Montadores de aparelhos e instrumentos de precisão e musicais \\
\hline & 75 & Joalheiros, vidreiros, ceramistas e afins \\
\hline & 76 & Trabalhadores das indústrias têxteis, do curtimento, do vestuário e das artes gráficas \\
\hline & 77 & Trabalhadores das indústrias de madeira e do mobiliário \\
\hline & 78 & Trabalhadores de funções transversais \\
\hline & 81 & Trabalhadores das indústrias de processos contínuos e outras indústrias \\
\hline & 82 & Trabalhadores de instalações siderúrgicas e de materiais de construção \\
\hline & 83 & Trabalhadores de instalações e máquinas de fabricação de papel, celulose e similares \\
\hline
\end{tabular}

(continua) 
(continuação)

\begin{tabular}{|ccl|}
\hline Grupo & Subgrupo & \multicolumn{1}{c|}{ Titulação } \\
\hline 84 & Trabalhadores da fabricação de alimentos, bebidas e fumo \\
86 & Operadores de instalação/produção/distribuição de energia; tratamento/distribuição de água \\
87 & Outros trabalhadores elementares industriais \\
91 & Trabalhadores de reparação e manutenção mecânica \\
95 & Polimantenedores \\
99 & Outros trabalhadores da conservação, manutenção e reparação \\
\hline 0 & & Membros das Forças Armadas e auxiliares \\
& 01 & Militares da Aeronáutica \\
03 & Militares do Exército \\
04 & Policiais militares \\
05 & Bombeiros militares \\
\hline
\end{tabular}

Fonte: Classificação Brasileira de Ocupações Domiciliar (CBO-Domiciliar). 